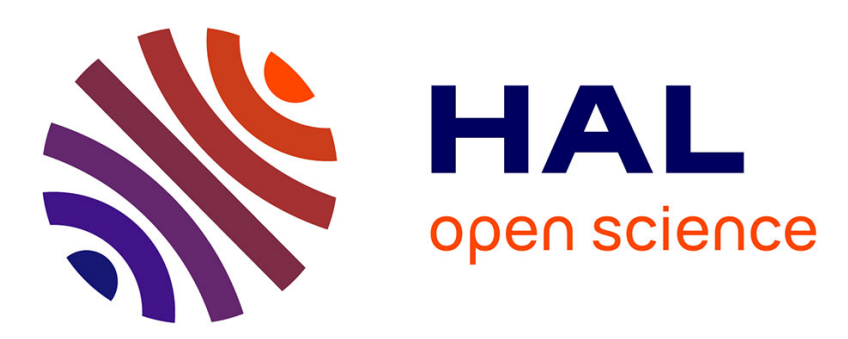

\title{
What is in a Name? Credit Assignment Practices in Different Disciplines
}

\author{
Tove Faber Frandsen, Jeppe Nicolaisen
}

\section{To cite this version:}

Tove Faber Frandsen, Jeppe Nicolaisen. What is in a Name? Credit Assignment Practices in Different Disciplines. Journal of Informetrics, 2010, 4 (4), pp.608-617. hprints-00515981

HAL Id: hprints-00515981

https://hal-hprints.archives-ouvertes.fr/hprints-00515981

Submitted on 8 Sep 2010

HAL is a multi-disciplinary open access archive for the deposit and dissemination of scientific research documents, whether they are published or not. The documents may come from teaching and research institutions in France or abroad, or from public or private research centers.
L'archive ouverte pluridisciplinaire HAL, est destinée au dépôt et à la diffusion de documents scientifiques de niveau recherche, publiés ou non, émanant des établissements d'enseignement et de recherche français ou étrangers, des laboratoires publics ou privés. 


\title{
What is in a Name? Credit Assignment Practices in Different Disciplines
}

\author{
Tove Faber Frandsen ${ }^{1} \&$ Jeppe Nicolaisen ${ }^{2}$ \\ 1tofr@litcul.sdu.dk; ${ }^{2}$ jni@iva.dk \\ ${ }^{1}$ University of Southern Denmark \\ Campusvej 55, DK-5230 Odense M, DENMARK \\ ${ }^{2}$ Royal School of Library and Information Science \\ Birketinget 6, DK-2300 Copenhagen S., DENMARK
}

\begin{abstract}
:
The paper reviews the literature on disciplinary credit assignment practices, and presents the results of a longitudinal study of credit assignment practices in the fields of economics, high energy physics, and information science. The practice of alphabetization of authorship is demonstrated to vary significantly between the fields. A slight increase is found to have taken place in economics during the last 30 years (1978-2007). A substantial decrease is found to have taken place in information science during the same period. High energy physics is found to be characterised by a high and stable share of alphabetized multi-authorships during the investigated period (1990-2007). It is important to be aware of such disciplinary differences when conducting bibliometric analyses.
\end{abstract}

Keywords: credit assignment; alphabetization; authorship; multi-authorship; bibliometrics 


\section{Introduction}

What are the advantages of being first-named author of a publication? van Praag and van Praag (2008: P782) argue that first-named authorship entails benefits in terms of (1) first-named authors are perceived by some to be those making the greatest contribution, (2) citation indices have for a long time only counted citations to first-named authors and consequently their citation counts are greater and (3) citations within articles are often shortened to '[first author] et al.' Consequently, being first-named contributes to the reputation and visibility of the author cited. Einav and Yariv (2006: 186) add another aspect to the list of benefits pointing to the fact that reference lists typically are ordered alphabetically and consequently, first named authors are easier to locate in the list.

Despite the evident advantages of being first-named author noted as early as in 1977 (Rudd, 1977) credit assignment practices have been demonstrated to vary from discipline to discipline (Engers et al., 1999) and even within disciplines (Laband, 2002; Joseph, Laband and Patil, 2005). Some disciplines place significant value on being the first author listed in a multi-authored article. In these disciplines authorship is not always listed alphabetically. Other disciplines place lesser value on being the first author listed, and authors are thus much more often listed in alphabetical order (Birnholtz, 2007). Yet, longitudinal studies of trends and tendencies in various disciplines are few. Studies combining credit assignment practices with trends in multi-authored publications such as hyper-authorship are even fewer.

According to Davenport and Cronin (2001), the practice of honorific authorship (the granting of a byline for purely social or political reasons) is a well-known phenomenon in the biomedical community that has inflated the levels of co-authorship into 'hyperauthorship'. This term was coined by Cronin (2001) who argued that changes in the conditions of scientific work and the associated reward structures have had significant impacts on the collective understanding of authorship. His study of credit assignment in biomedicine shows that the contemporary author "is no longer the sole conceiver, fabricator, and owner of the published article. Instead, today's biomedical journal article is the progeny of occasionally massive collaborations, the individual members of which may have minimal involvement in the fashioning of the literary end-product itself, with the act of writing being delegated to a subgroup or designated spokespersons” (Cronin, 2001: 567). Cronin and Franks (2006) find that intense co-authorship and subauthorship collaboration are defining features of contemporary research in the life sciences. Persson, Glänzel and Danell (2004) find the same tendencies in their study of all papers indexed in the Science Citation Index (1980-2000). Their results show that the number of papers have grown by 36 percent between 1980 and 1998, the number of authors have grown by 64 percent, the amount of citations received by 76 percent and total references made by 93 percent. These almost inflationary growth rates led the authors to call for relative and strictly normalised indicators in bibliometric trend analyses and medium-term or longterm studies. 
This paper reports the results of a comparative study of credit assignment practices in the fields of economics and information science for the period 1978-2007, and high energy physics for the period of 1990-2007 (journals representing the field are not available for analysis before 1990). High energy physics is chosen as it is a field characterized by hyper-authorship. Economics was chosen because it is a discipline characterised by a remarkably high share of papers with names listed in alphabetical order (Engers et al., 1999). Finally, Information science is chosen as we expect that the majority of information scientists are likely aware of the increased visibility and attention received by first-authors as well as the potential bibliometric consequences of using the alphabetical principle when listing authors. The paper is organized as follows: The next section provides an overview of related research. The following sections present the methods of data collection and processing followed by results, discussions and conclusions.

\section{Credit assignment practices}

According to Laband and Tollison (2000) intellectual collaboration can take the form of formal coauthorship as well as informal (e.g. professional meetings, informal commentary or presentations at seminars). Despite the sparse attention in the literature, they consider the importance of collegiality to be universally acknowledged by scholars. Drawing the line between the informal and the formal collaboration is however, not a trivial task. Savitz (1999) argue that many people contribute to a scientific project and the magnitude of the contributions range from trivial to crucial. Attention is often called to the 'gift authorship' that describes attributing authorship to people with limited intellectual contribution to the research project (e.g. the leader of a scientific group or the person(s) providing the funding for the project). Flanagin et al. (1998) conduct a case study and find that articles with honorary authors occur in shares ranging from 11 to 25 percent in three medical journals. Bates et al. (2004) finds shares ranging from 4 to 60 percent in three medical journals (with an overlap of two journals with the aforementioned study).

Quite the opposite of the gift authorship is the 'ghost authorship' that characterises individuals with considerable intellectual contribution that are not attributed authorship. Flanagin et al. (1998) conduct a case study and find that articles with ghost authors occur in shares ranging from 7 to 16 percent in three medical journals and 2 percent show evidence of both gift and ghost authorship. A list of authors do not provide information on what a specific author can be held responsible for and particularly in the case of mistakes or misconduct liability can be difficult to allocate among authors (Kennedy, 2003). To address the problem with multiple authors the 'film credits' approach has been suggested which list contributors with their individual contribution (Garfield, 1982). Several medical journals have changed the definition of authorship employing a model that allows readers to distinguish between different types of authorship. Authors are described as contributors and guarantors (see e.g. Smith, 1997). 
Having determined the appropriate list of authors for a publication the problem of ordering the names remains. The authors can state in a note that some (or all) of the authors have contributed equally to the publication just as the publication can have more than one corresponding author which is also a sign of "equal first authors". There has been a rise in the use of equal contributors (Hu, 2009), however, it does not solve the issue of ordering the names. A number of possible ordering principles exist. According to van Praag and van Praag (2008) two strategies can be used: the alphabetical or the non-alphabetical. Chandra et al. (2006) outline principles and practices of ordering names which could be regarded as strategies and they add two: randomness (e.g. a coin flip) and subdividing authorship across different publications, with some joint and some separate publications covering different pieces of a collaborative project. The former is a nonalphabetical strategy whereas the latter is in fact not an ordering principle as it implies that there may be instances of ghost authorship but does mention how the authors should be ordered.

The lexicographic listing of authors can be considered an expression of the authors having contributed equally to the paper. Listing alphabetically can also be caused by authors being hesitant to violate the norm of listing alphabetically which is an equilibrium solution (Engers et al., 1999). The authors of a publication may not necessarily have the same perception of the size and character of each author's contribution and to avoid a wearisome negotiation of ordering the lexicographic principle may be the solution. However, as Maciejovsky, Budescu and Ariely (2009) also argue, a calculating and strategically planning author would be in search of co-authors with last names later in the alphabet than themselves. The alphabetical listing can also be a case of listing authors randomly as suggested by Lake (2010). The fewer the authors the greater possibility of listing the authors alphabetically by chance.

The non-alphabetical strategy can be used to indicate "author-rated level of contribution" (Baerlocher et al., 2007). This typically implies that the lead author have contributed with a disproportionate amount of work. Baerlocher et al. (2007) have analysed types of contributions for various author positions and determined patterns of author order and type of contribution. Drenth (1998) finds that a rise in the number of authors in British Medical Journal over 20 years is mainly explained by a rise in authorship among professors and department chairpersons. In some fields (e.g. medicine) they are typically listed last (Drenth, 1998) and in other fields (e.g. high energy physics) they are typically listed in the alphabetical order (Birnholz, 2006). Laband and Tollison (2000) suggest that grant funding may be related to the use of nonalphabetical listing as the fund-raiser may be named as (first)author in disciplines were grant money includes funding a lab and a team of potential contributors to the scientific production process whereas in other disciplines grant money only support the principal investigator. However, they find little evidence to support their hypothesis. The non-alphabetical strategy can also be a merit-based ordering as a result of differences in 
hierarchical positions, the relative academic reputations of co-authors (van Praag and van Praag, 2008) ${ }^{1}$ or age (Liang et al., 2001; Liang, Liu \& Rousseau, 2004). A principle of rotation can also lead to the use of the non-alphabetical strategy. A research team can decide to let first author attribution rotate among authors along with a footnote stating that the work is collaborative work with authors contributing equally (Savitz, 1999).

Interpreting the author contributions of multi-authorered papers is anything but simple. Savitz (1999: 401) argues that "information about the nature of the collaboration is encrypted in the sequence of authors, obvious to some readers and certain to be misunderstood by other". Kennedy (1999) stresses that "if quality judgements about individuals are to be made on the basis of their personal contributions, then the judges better know what they did”. Majciejovsky, Budescu and Ariely (2009: 597) discuss the implications of weak ordering norms and implicitly also offers an explanation of why ordering norms exist:

First, strong norms render inferences about contribution credits more accurate (i.e., more likely to reflect the authors' intentions). Second, when the norms are violated, researchers are penalized in terms of their assigned contribution credits. Third, the penalty for mixed contribution signals is more complex when the norms are alphabetical, because a nonalphabetical ordering on one paper questions the ordering norm of other (alphabetically ordered) papers. Fourth, the signal about individual contributions is least clear for two-authored papers, where alphabetical ordering either reflects equal contribution or relative contribution (when the ordering happens to coincide with the surnames' alphabetical order).

Authors working within disciplines where publications are predominantly listing authors using the alphabetical principle are potential victims of alphabetical discrimination as stated by Einav and Yariv (2006). It can be argued that it is beneficial for authors whose names come early in the alphabet, since being the first author implies certain advantages. Efthyvoulou (2008) suggest that it may be the other way around because having a name that comes early in the alphabet may actually be harmful because an author with a name early in the alphabet can never signal a higher than proportional contribution to a paper. The alphabetical principle have with varying degrees of success been associated with a smaller production of publications of authors in the second half of the alphabet (Chambers, Boath \& Chambers, 2001; Laband \& Tollison, 2000). Salary has also been related to the alphabetical principle. Rudd (1977) finds no relation in chemistry whereas Efthyvoulou (2008) finds that in economics faculty members with earlier last name initials are more likely to get employment at high standard research departments.

\footnotetext{
${ }^{1}$ It should be noted that the term merit-based assignment can have different meanings. Laband and Tollison uses the term merit-based assignment to indicate that the principal contributor is listed as the first author (Laband \& Tollison, 2000: 659).
} 
Einav and Yariv (2006) stress that authors are aware of the alphabetical discrimination and respond accordingly. They find a relationship between alphabetical placement and participation in coauthored projects and willingness to list non-alphabetically. Van Praag and van Praag (2008) also find evidence that authors are aware of the importance of name ordering and take precautions. They find several characteristics of the composition of authors that determine the decision to list non-alphabetically. The order of authorship is affecting the fraction of production team given authorship rights/acknowledgements. Laband (2002) finds that 89 percent of economics articles are listed alphabetically whereas this is only the case for 44 per cent within agricultural economics. Conversely, 77 percent of agricultural economics articles are multi-authored whereas only 65 percent within economics are co-authored. The loss for the main contributing author is greater when he or she risks not being the first named author. Consequently, a response to the alphabetical discrimination for authors with surnames in the second half of the alphabet is a reduced willingness to co-author. The response is observed in economics where the average number of authors is about 2 (Laband \& Tollison, 2000) and may not be valid in disciplines characterised by a high number of hyper-authorships. An example of such a discipline is high energy physics:

HEP has a longstanding tradition of extremely inclusive authorlists. From the recent past into the present, this has meant alphabetically listing all members of a collaboration as authors on any article written by any member of that collaboration (provided, of course, that the article is based in data from that particular project) (Birnholtz (2006: 1762).

\section{Methods}

To illustrate the development over time in the sum of papers with (author) names listed in alphabetical order, data was collected from journals representing three fields: two social science disciplines (economics and information science (IS)) and one Science discipline (high energy physics (HEP)). As noted previously, Economics was selected because it is a social science characterised by a remarkably high share of papers with names listed in alphabetical order (Engers et al., 1999). IS was selected because it is a discipline studying authorship practices, citation indices, etc., and consequently a discipline whose authors may know about the potential benefits of first-named authorships. Finally, HEP is selected as a discipline characterised by hyper-authorship as well as high degree of alphabetization.

It is important that the selected journals are representative for their respective disciplines, since we would like our results to be as general as possible. For the analysis of economics the list of 27 core journals identified by Diamond (1989) sets the basis ${ }^{2}$. For the analysis of IS the list of 12 core journals by

\footnotetext{
${ }^{2}$ The list has been assessed critically (e.g., Burton \& Phimister, 1995), and there exist a number of alternative lists (see e.g. Beed \& Beed (1996) for an overview; Axarloglou \& Theoharakis, 2003; Bräuninger \& Haucap, 2001; 2003; Sutter
} 
White and McCain (1998) is used ${ }^{3}$. The HEP journals is selected using the list of core journals identified by SCOAP (scoap3.org). Appendix 1 provides an overview of the included journals. The list of HEP journals is considerably shorter than the economics and IS lists, however, the shorter HEP journals list results in the greatest number of included publications. The average number of included publications is 393 per year for IS, 1433 for economics and 3716 for HEP.

The data collection was restricted to include research articles published between 1978 and 2007. For HEP the data collection is restricted to begin in 1990 because data is not available earlier. For each article data were collected for the following variables: year of publication, number of authors, and whether authors of multi-authored articles are listed alphabetically.

\section{Results}

The results demonstrate the development in authorships and the share of alphabetized multi-authorships. The figures are shown using moving averages as it smoothes data series and makes it easier to spot trends. A moving average is calculated as the average over a period of time that is constantly updated by removing the oldest value and adding the newest value. The moving averages are calculated in intervals of three years (note: moving averages for the first and last years are only calculated in intervals of two years).

Figures 1 through 3 present the development in the number of authors per article in economics and IS journals from 1978 to 2007, and HEP journals from 1990 to 2007. In the beginning of the period the majority of papers in the 27 economics journals were single authored as more than 65 per cent of all articles had only one author. This number decreases substantially during the following 30 years. In 2007 the share actually is less than half of the value 29 years earlier, as only a little over 30 per cent of all articles had only one author. Correspondingly, the share of multi-authorships increases, and in 2007 the majority of articles were written by two authors. These results are in accordance with results found by Hudson (1996) who analyzed eight leading economics journals using observations from the period 1950 to 1993.

\& Kocher, 2001). However, Diamond's list has been used as starting point for other analyses of economics (e.g., Hudson, 1996), and is often used to justify the included journals on a shorter list (e.g., Kalaitzidakis, Mamuneas \& Stengos, 1999; Medoff, 2006).

${ }^{3}$ A number of alternative lists have been proposed (e.g.; Noyons \& Van Raan, 1998; Åström, 2007). Yet, the list by White and MacCain (1998) has been used successfully as a starting point for other analyses (e.g., Nicolaisen, 2002). 


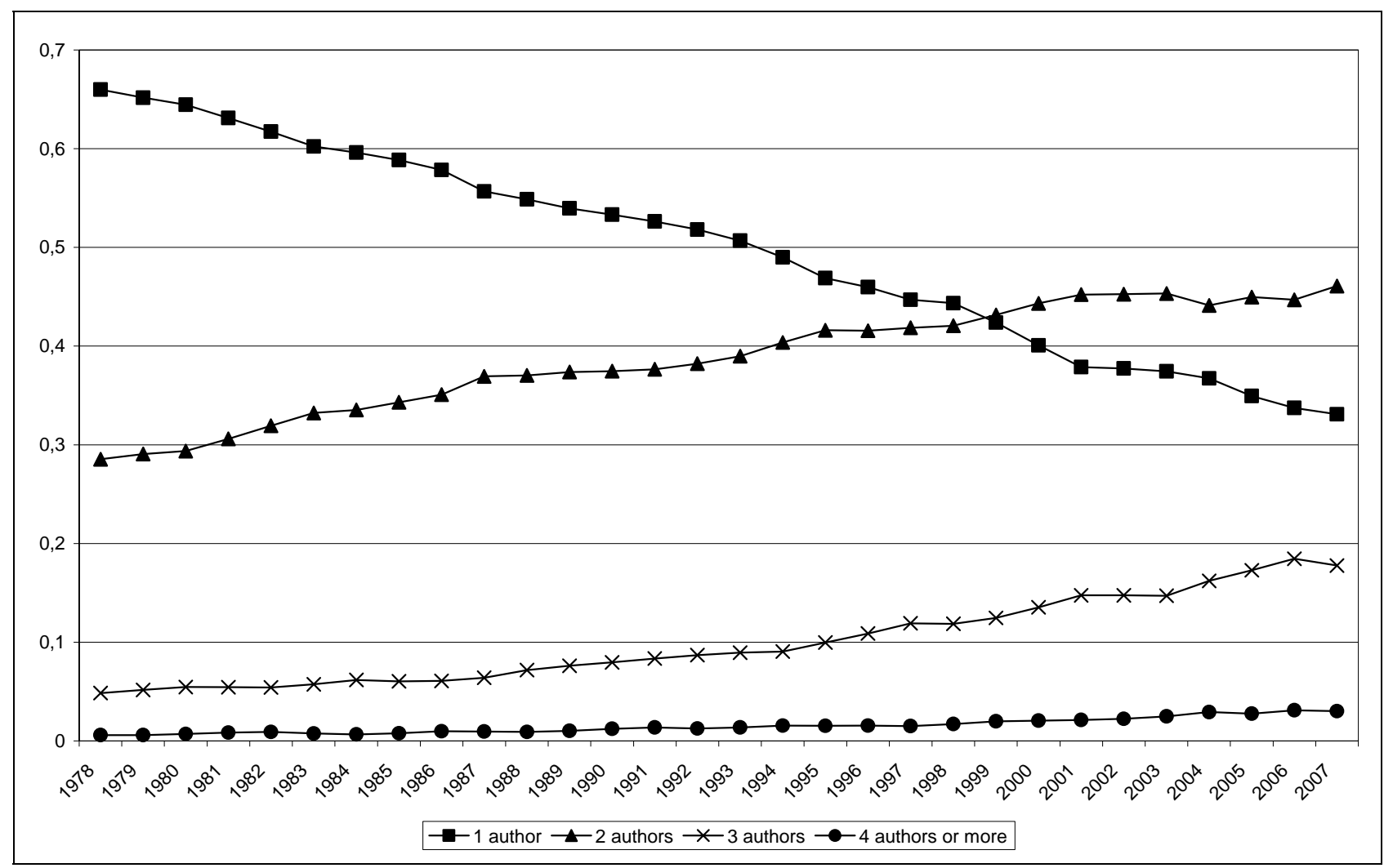

Figure 1. Share of single and multi authorships authorship in economics.

In the 12 IS journals a similar trend can be seen in the development in multi-authorships over time, although the single-authored article prevails as the dominating type of authorship, because the increase in multiauthorships is distributed more evenly. The increase in authorship collaboration is in accordance with results by Lipetz (1999) who found that the number of multi-author articles in one IS journal have been increasing each decade since 1970 


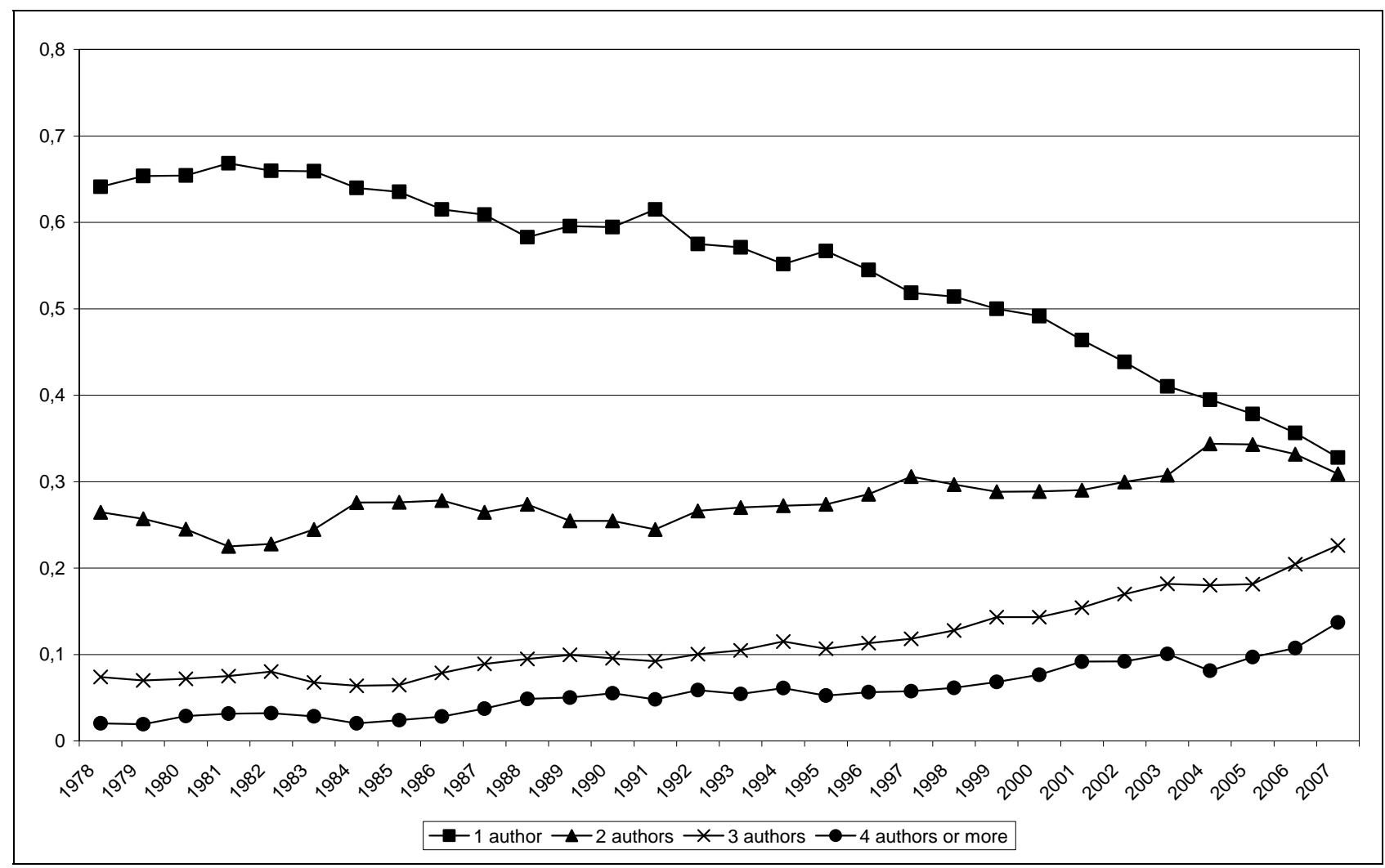

Figure 2. Share of single and multi authorships authorship in information science.

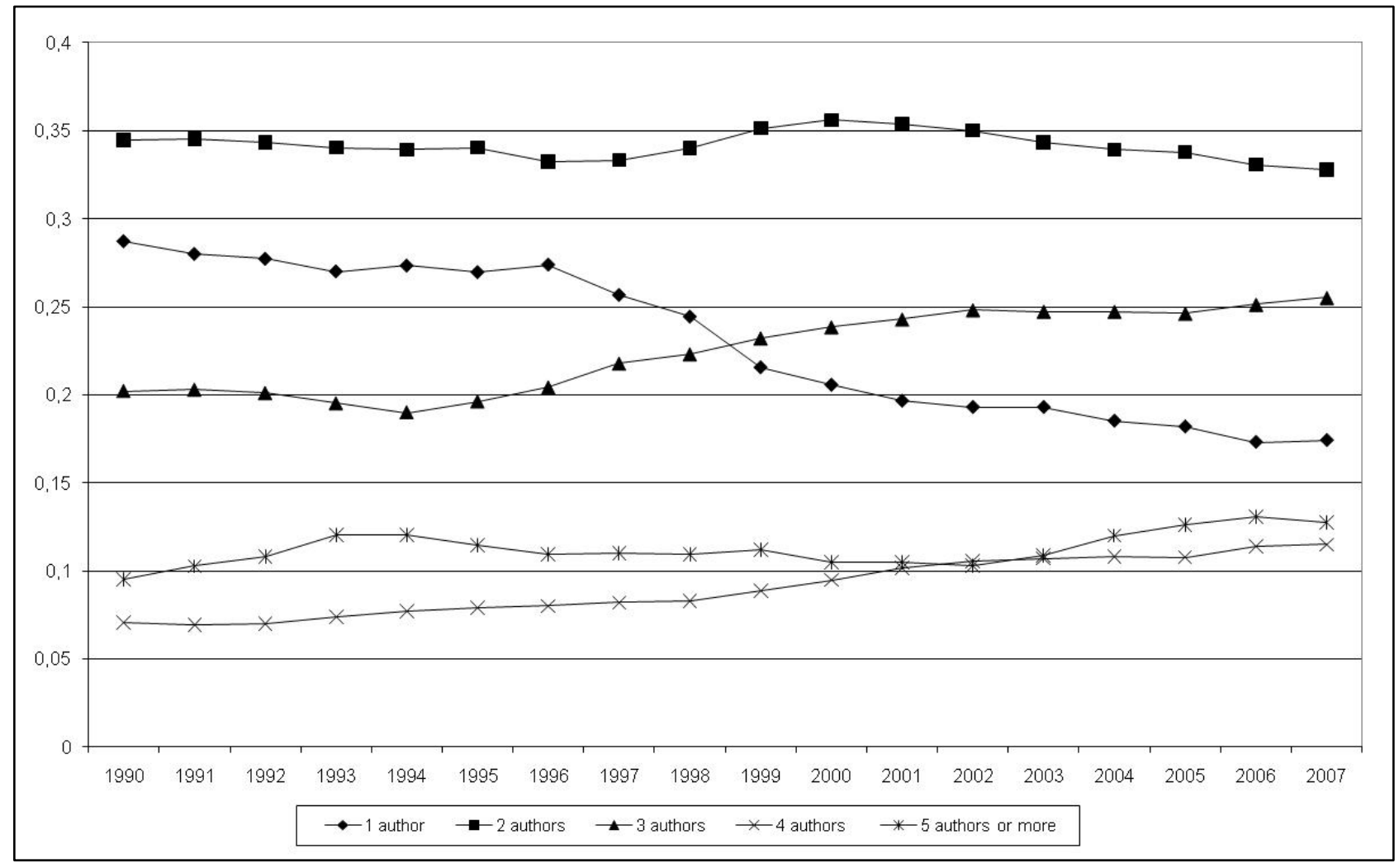

Figure 3. Share of single and multi authorships authorship in high energy physics. 
The lowest number of single-authored publications in these three fields is found in HEP. In 1990 the share of single-authored publications is 29 per cent and in 2007 this share has decreased to 17 percent. On the other hand, publications with 4 or more authors make up as much as 24 per cent in 2007.

The increase in multi-authorships in all three fields is well-documented as a general trend in the social sciences, the sciences, and in the arts and humanities, although it varies greatly by field (see e.g., Borgman \& Furner, 2002). However, the crucial issue for the point made in the present paper is the shares of alphabetized multi-authorships. The development in the shares of alphabetized multi-authorships over time from 1978 (1990) to 2007 is shown in figures 4 through 6. Starting with economics, it is clear from Figure 4 that this discipline has a very high share of alphabetized multi-authorships, as roughly three fourths of all multi-authorships are alphabetized. The level of alphabetization is lower for 4 and more authors than for 3 authors, which is also lower than for 2 authors. This is expected as an increase in the number of authors reduces the probability for assigning authorship in alphabetical order by pure chance. The development over time in economics is remarkable as the shares of alphabetized multi-authorships increase over time.

Turning to Figure 5, we see that the level of alphabetized authorship is much lower in IS, especially in articles with 3 or more authors. Within this discipline less than half of all multi-authored articles have alphabetized author names. When reducing the probability of alphabetization by pure chance, we see a picture of a discipline where the use of alphabetization of authors is generally uncommon. Furthermore, it is evident that the shares are decreasing over time. 


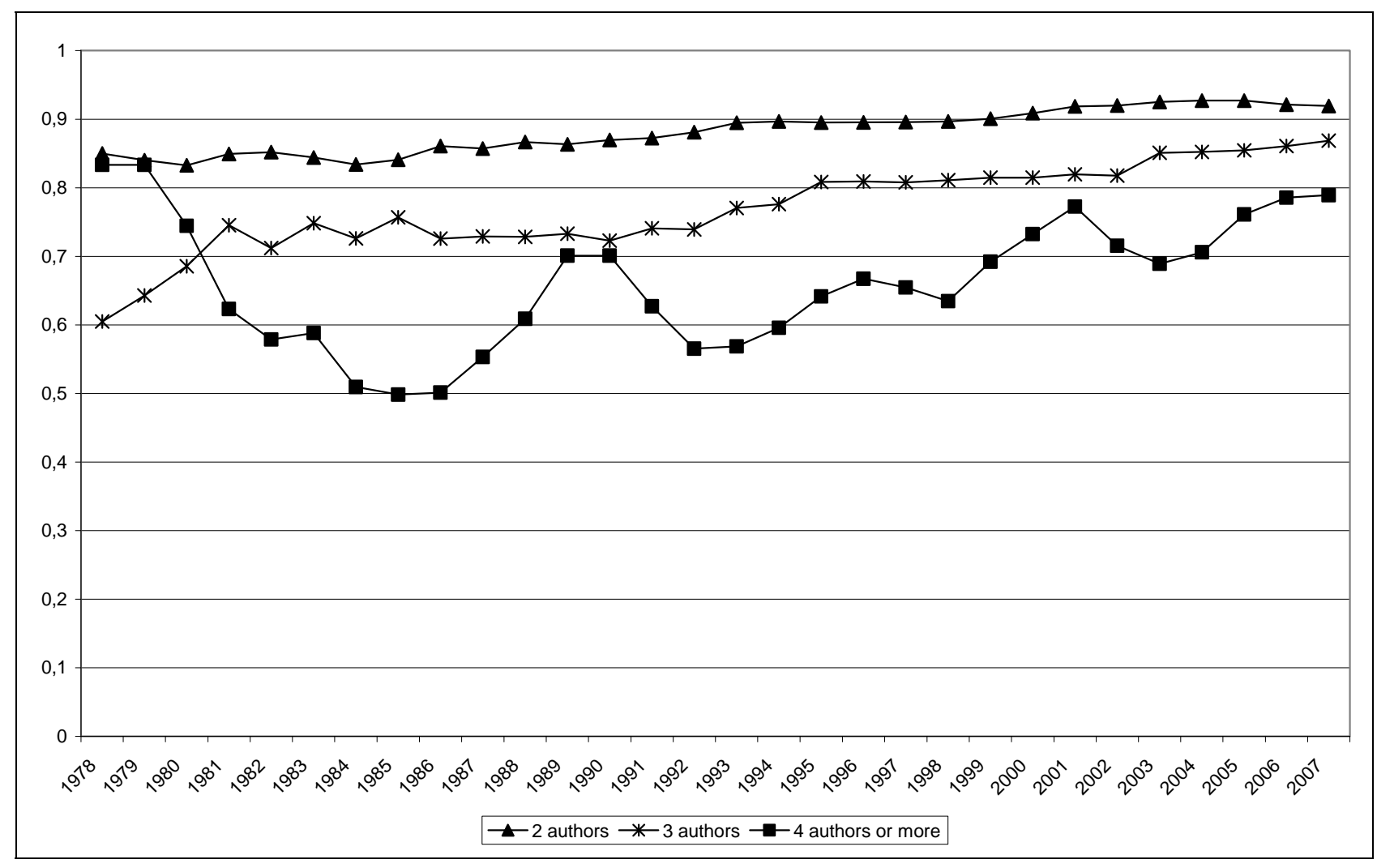

Figure 4. Percentage of articles in economics with names listed in alphabetical order by number of co-authors

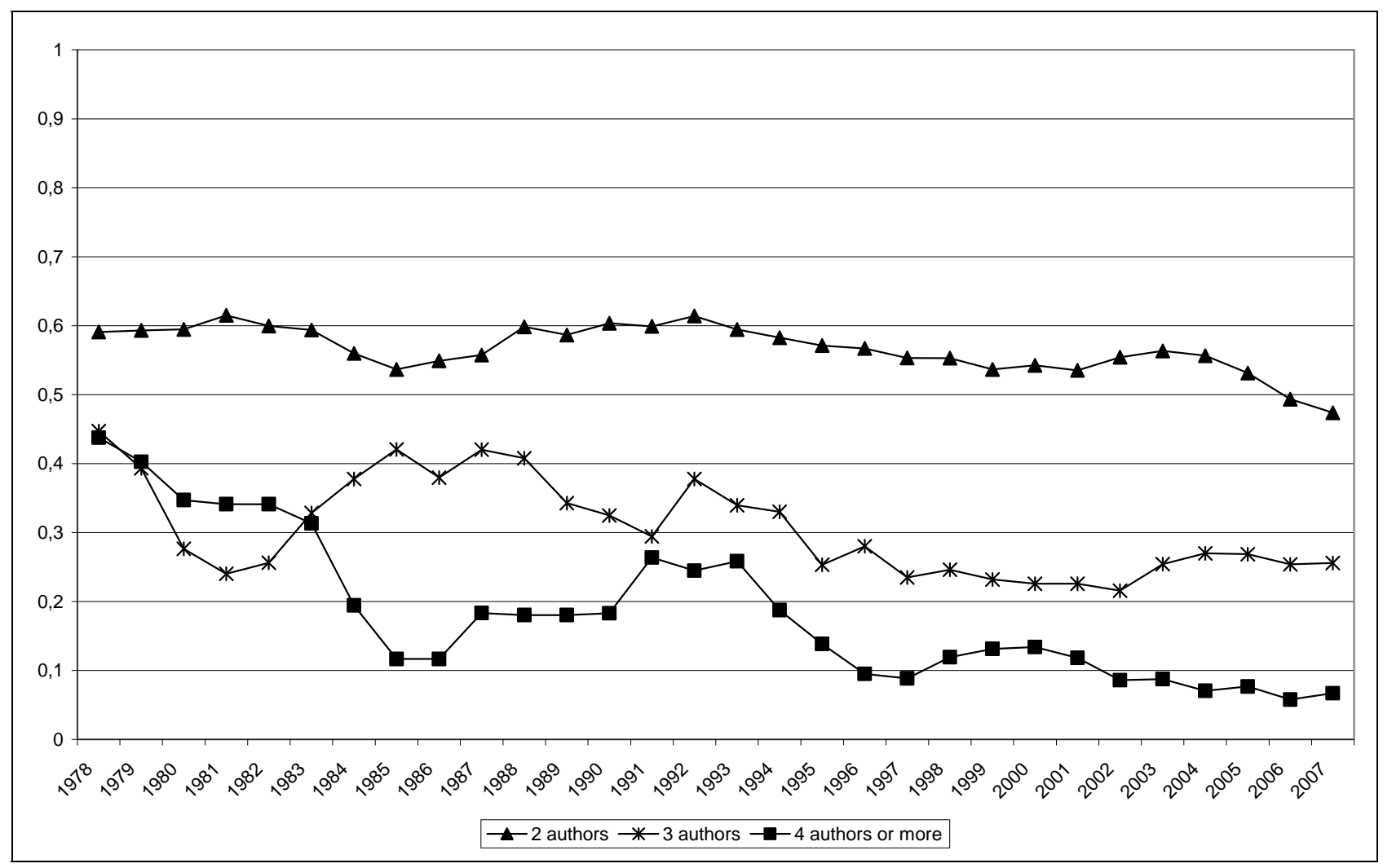


Figure 5. Percentage of articles in information science with names listed in alphabetical order by number of co-authors

Finally, figure 6 shows that HEP is characterised by a high share of alphabetized multiauthorships, as roughly three fourths of all multi-authorships are alphabetized. Again the level of alphabetization decreases as the number of authors increases which we would expect as an increase in the number of authors reduces the probability for assigning authorship in alphabetical order by chance. Consequently, HEP is like economics a field where author order is typically alphabetical, however unlike economics the development over time shows relatively stable shares for 2 to 4 authors whereas the share for 5 authors or more seems to be increasing.

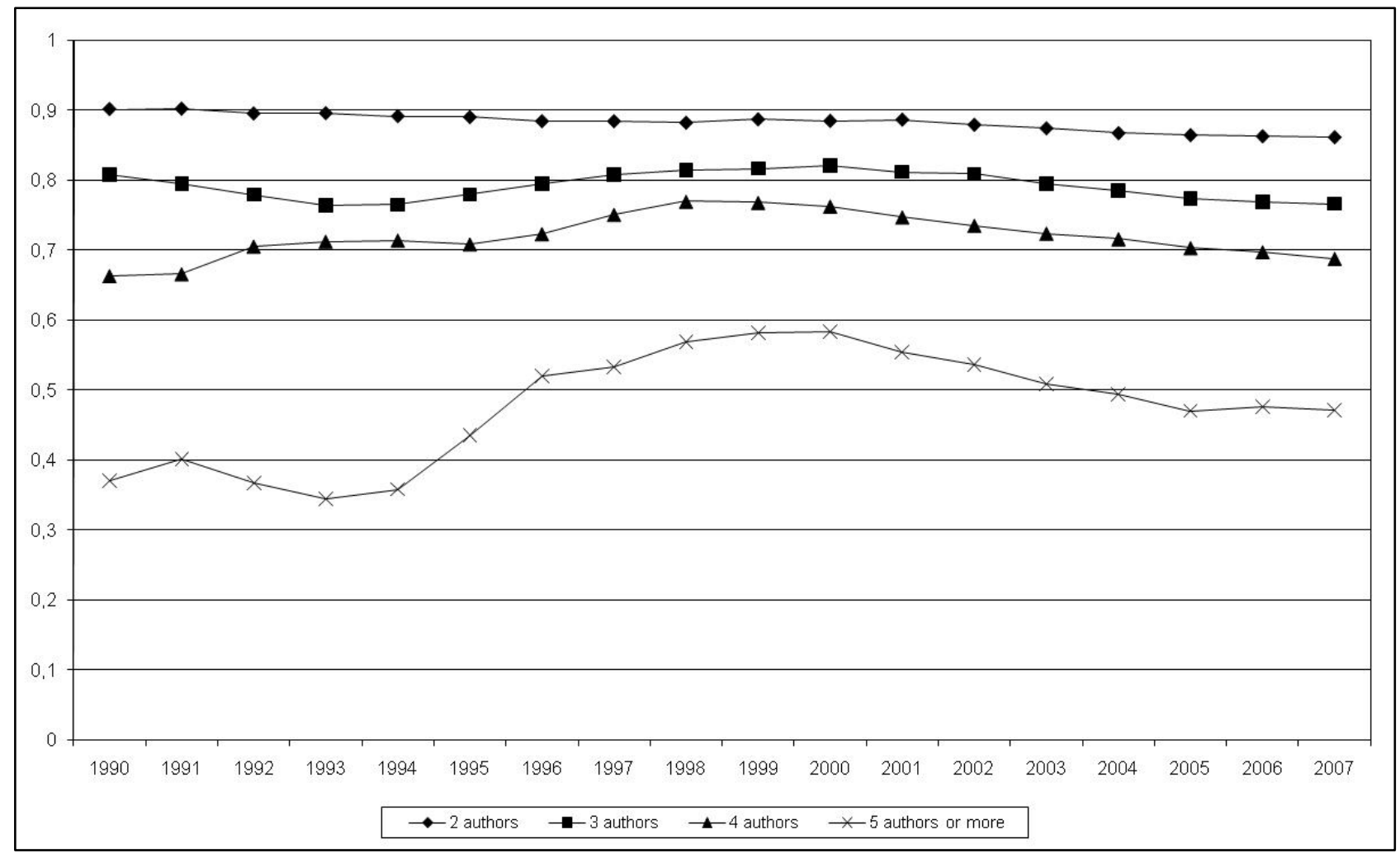

Figure 6. Percentage of articles in high energy physics with names listed in alphabetical order by number of co-authors

Table 1 confirms the increasing tendency to alphabetization in economics and the decreasing tendency in IS. The table contains an overview of 10 univariate linear regressions. The dependent variable is the share of articles with authors in alphabetical order and the independent variable is time period (year). All regressions of economics and IS publications are based on 30 observations (years) whereas analyses of HEP are based on 18 observations. The coefficients in Table 1 can be interpreted as the yearly change in the share of articles with authors listed alphabetically during the time period 1978 to 2007. The articles in IS written 
by 4 or more authors serve as an example: The coefficient -.010 means that on average over a period of 10 years, the share of articles with authors listed alphabetically decreased by 10 percentage points.

\begin{tabular}{llll}
\hline & R square & Coefficient of dependent variable & P value of coefficient \\
\hline Economics: 2 authors & .78 & .003 & $<.01$ \\
Economics: 3 authors & .64 & .007 & $<.01$ \\
Economics: 4 authors or more & .58 & .004 & .201 \\
LIS: 2 authors & .28 & -.003 & $<.01$ \\
LIS: 3 authors & .20 & -.005 & $<.05$ \\
LIS: 4 authors or more & .56 & -.010 & $<.01$ \\
HEP: 2 authors & .79 & -.002 & $<.01$ \\
HEP: 3 authors & .01 & .000 & .70 \\
HEP: 4 authors & .49 & .002 & .38 \\
HEP 5 authors or more & .23 & .009 & $<.05$ \\
& & & \\
\hline
\end{tabular}

Table 1. Univariate linear regression. Dependent variable is the share of articles with authors in alphabetical order. Independent variable is year. Regressions with p-values of the coefficient $<.05$ are marked with bold.

In general the coefficients for economics are positive, confirming a statistically significant increasing use of alphabetization. The regression for 4 authors or more was not statistically significant at the .05 level for economics due to a relatively small number of articles in this category during the first 10 to 15 years (on average only 12 articles with 4 or more authors a year the first 15 years in comparison with 35 on average the last 15 years). The coefficients for IS are all negative, which oppositely confirms a statistically significant decreasing use of alphabetization. Both in economics and IS the coefficients increase as the number of authors increases (disregarding the regression for 4 authors or more that was not statistically significant at the .05 level for economics). This is at least to a certain extent related to reducing the probability of chance. However, it could also be related to a greater need of signalling the assignment of priority. The analyses of HEP provide two regressions statistical significant at the .05 level. Articles with two authors show a decrease in the use of alphabetization whereas articles with 5 authors or more are increasingly ordering authors alphabetically. 


\section{Discussion and conclusion}

It is evident that bibliometric indicators have positive steering effects on the scientific community. They may, for instance, stimulate publication activity and motivate researchers to collaborate more. Yet, bibliometric indicators may also have negative steering effects (Weingart, 2005). According to Glänzel (2006) these effects may be classified in at least four main categories: Exaggerated collaboration, inflation of publication output by splitting up publications to least publishable units, inflation of citation impact by selfcitations, and the formation of citation cliques. We suggest expanding the categorization of possible negative steering effects with a fifth category for changes in credit assignment. The results of our study show a significant drop in alphabetized IS multi-authorships during the investigated 30 year period, and a significant increase in alphabetized multi-authorships in economics during the same period. The HEP results are a little mixed, but characterized by a high share of alphabetized authorships. Whether these results are caused alone by differences in awareness of the citation analytical consequences of alphabetization of authorship is undecided. Nevertheless, our results demonstrate co-variation between the use of ISI-based citation analysis for research evaluation purposes and the use of the alphabetic principle among authors who are likely to know about the bibliometric consequences of this practice. The last four decades have witnessed a steady increase in the use of ISI-based citation analyses for research evaluation purposes (see e.g., Moed, 2005; Monastersky, 2005; Wouters, 1999) which are judged to correlate well with our findings of the decline in alphabetization of authorship in IS.

When using ISI-data for research evaluation purposes there are many pitfalls and obstacles that need to be tackled. One is the problem that only first authors are listed in the cited references. Focusing on multi-authored papers, citation counts for the economist $\mathrm{Z}$ will consequently be lower than for the economist $\mathrm{A}$. The same goes for $\mathrm{Z}$ and $\mathrm{A}$ in HEP, but not necessarily for $\mathrm{Z}$ and $\mathrm{A}$ in IS. These disciplinary differences need to be accounted of as ones results may otherwise be wrong or at best flawed. Most of us are aware of this. By "us” is meant us bibliometricians who in one way or another are applying ISI-data to our studies of Science, scientists, research collaboration, -communication, etc. The problem is, however, that we are not the only ones conducting or interpreting such work. Bibliometric studies are also conducted by other groups of people. For instance, many countries are currently working on developing their own research performance indicators. The people engaged in this work are often practitioners (administrators and others) without the same knowledge and understanding as trained bibliometricians. It is consequently important to inform this group of practitioners about the disciplinary differences that affect the outcome of bibliometric studies. In order to do this we need systematic documentation that demonstrates these differences. 


\section{Literature}

Axarloglou, K. \& Theoharakis, V. (2003). Diversity in economics: An analysis of journal quality perceptions. Journal of the European Economic Association, 1(6): 1402-1423.

Baerlocher, M. O.; Newton, M.; Gautam, T.; Tomlinson, G. and Detsky, A. S. (2007). The meaning of author order in medical research. Journal of Investigative Medicine, 55: 174-180.

Bates, T.; Anic, A.; Marusic, M. and Marusic, A. (2004). Authorship criteria and disclosure of contributions - Comparison of 3 general medical journals with different author contribution forms. Jama - Journal of the American Medical Association, 292(1), 86-88.

Beed, C. \& Beed, C. (1996). Measuring the quality of academic journals: The case of economics. Journal of Post Keynesian Economics, 18(3): 369-396.

Birnholtz, J. P. (2006). What does it mean to be an author? The intersection of credit, contribution , and collaboration in science. Journal of the American Society for Information Science and Technology, 57(13): 1758-1770.

Birnholtz, J.P. (2007). When do researchers collaborate? Toward a model of collaboration propensity. Journal of the American Society for Information Science and Technology, 58(14): 2226-2239.

Borgman, C.L. \& Furner, J. (2002). Scholarly communication and bibliometrics. Annual Review of Information Science and Technology, 36(1): 3-71.

Bräuninger, M. \& Haucap, J. (2001). Was Ökonomen lesen und schätzen: Ergebnisse einer Umfrage. Perspektiven der Wirtschaftspolitik, 2: 185-210.

Bräuninger, M. \& Haucap, J. (2003). What economists think of their journals and how they use them: Reputation and relevance of economics journals. Kyklos, 56(2): 175-197.

Burton, M.P. \& Phimister, E. (1995). Core journals: A reappraisal of the Diamond list. The Economic Journal, 105(429): 361-373. 
Chambers, R.; Boath, E. and Chambers, S. (2001). The A to Z of authorship:analysis of influence of initial letter of surname on order of authorship. British Medical Journal, 323,1460-1461.

Chandra, K.; Gandhi, J.; King, G.; Lupia, A. and Mansfield, E. (2006). Report of APSA Working Group on Collaboration. Available at http://www.apsanet.org/imgtest/CollaborationReport08-09-06.pdf [June 23, 2010].

Cronin, B. (2001). Hyperauthorship: A postmodern perversion or evidence of a structural shift in scholarly communication practices? Journal of the American Society for Information Science and Technology, 52(7): 558-5698.

Cronin, B. \& Franks, S. (2006). Trading cultures: Resource mobilization and service rendering in the life sciences as revealed in the journal article's paratext. Journal of the American Society for Information Science and Technology, 57(14): 1909-1918.

Davenport, E. \& Cronin, B. (2001). Who dunnit? Metatags and hyperauthorship. Journal of the American Society for Information Science and Technology, 52(9): 770-773.

Diamond, A.M. (1989). The core journals of economics. Current Contents, 1: 4-11.

Drenth, J. P. H. (1998). Multiple authorship. The contribution of senior authors. JAMA-Journal of the American Medical Association, 280(3), 219-221.

Einav, L. and Yariv, L. (2006). What's in a surname? The effects of surname initials on academic success. Journal of Economic Perspectives, 20(1): 175-188.

Engers, M., Gans, J.S., Grant, S., and King, S.P. (1999). First-author conditions. Journal of Political Economy, 107(4): 859-883

Efthyvoulou, G. (2008). Alphabet Economics: The link between names and reputation. Journal of SocioEconomics, 37(3), 1266-1285.

Flanagin, A.; Carey, L. A.; Fontanarosa, P. B.; Phillips, S. G.; Pace, B. P.; Lundberg, G.D.; Rennie, D. (1998). Prevalence of articles with honorary authors and ghost authors in peer-reviewed medical journals. JAMA-Journal of the American Medical Association, 280(3) 222-224. 
Garfield E. (1982), More on the ethics of scientific publication: abuses of authorship attribution and citation amnesia undermine the reward system of science. Current Contents, 30, 5-10.

Glänzel, W. (2006). The 'perspective shift' in bibliometrics and its consequences (Keynote presentation). First International Conference on Multidisciplinary Information Sciences \& Technologies. PowerPoint presentation available at: http://www.slideshare.net/inscit2006/the-perspective-shift-in-bibliometrics-and-itsconsequences [January 15, 2010].

Hu, X. (2009). Loads of special authorship functions: Linear growth in the percentage of equal first authors and corresponding authors. Journal of the American Society for Information Science and Technology, 60(11), 2378-2381.

Hudson, J. (1996). Trends in multi-authored papers in economics. Journal of Economic Perspectives, 10(3): 153-158.

Kalaitzidakis, P., Mamuneas, T.P. \& Stengos, T. (1999). European economics: An analysis based on publications in the core journals. European Economic Review, 43(4-6): 1150-1168.

Kennedy, D. (2003). Multiple authors, multiple problems. Science, 301: 733.

Joseph, K.; Laband, D. N. and Patil, V. (2005). Author order and research quality. Southern Economic Journal, 71(3): 545-555

Laband, D. N. (2002). Contribution, attribution and the allocation of intellectual property rights: Economics versus agricultural economics. Labour economics, 9: 125-131.

Laband, D. N. and Tollison, R. D. (2000). Intellectual collaboration. Journal of Political Economy, 108(3): 632-662

Lake, D. A. (2010). Who's on First? Listing Authors by Relative Contribution Trumps the Alphabet. Political Science \& Politics, 43(1), 43-47.

Liang, L. M.; Kretschmer, H.; Guo, Y.Z.; Beaver, D. D. (2001). Age structures of scientific collaboration in Chinese computer science. Scientometrics, 52(3), 471-486. 
Liang, L.; Liu, J. and Rousseau, R. (2004), Name order patterns of graduate candidates and supervisors in Chinese publications: A case study of three major Chinese universities. Scientometrics, 61(1), 3-18.

Lipetz, B. (1999). Aspects of JASIS authorships through five decades. Journal of the American Society for Information Science, 50(11): 994-1003.

Maciejovsky, B.; Budescu, D. V. and Ariely, D. (2009). The Researcher as a Consumer of Scientific Publications: How Do Name-Ordering Conventions Affect Inferences About Contribution Credits? Marketing Science, 28(3), 589-598.

Medoff. M.H. (2006). The efficiency of self-citations in economics. Scientometrics, 69(1): 69-84.

Moed, H.F. (2005). Citation analysis of scientific journals and journal impact measures. Current Science, 89(12): 1990-1996.

Monastersky, R. (2005). The number that's devouring science. The Chronicle of Higher Education, 52(8): A12. Available at: http://chronicle.com/free/v52/i08/08a01201.htm [January 15, 2010]

Nicolaisen, J. (2002). Structure-based interpretation of scholarly book reviews: A new research technique. Proceedings of the Fourth International Conference on Conceptions of Library and Information Science: 123-135.

Noyons, E.C.M. \& Van Raan, A.F.J. (1998). Mapping Scientometrics, Informetrics, and Bibliometrics. Available at: http://www.cwts.nl/ed/sib/home.html [January 15, 2009].

Persson, O, Glänzel, W. \& Danell, R. (2004). Inflationary bibliometric values: The role of scientific collaboration and the need for relative indicators in evaluative studies. Scientometrics, 60(3): 421-432.

van Praag, C. M. and van Praag, B. M. S. (2008). The benefits of being economics professor A (rather than Z). Economica, 75: 782-796.

Rudd, E. (1977). The Effect of Alphabetical Order of Author Listing on the Careers of Scientists Social Studies of Science, 7(2), 268-269. 
Savitz, D. A. (1999). What can we infer from author order in epidemiology? American Journal of Epidemiology, 149(5): 401-403.

Smith, R. (1997): Authorship is dying: long live contributorship. British Medical Journal, 315(7110): 696.

Sutter, M. \& Kocher, M. (2001). Tools for evaluating research output: Are citation-based rankings of economics journals stable? Evaluation Review, 25(5): 555-566.

Weingart, P. (2005). Impact of bibliometrics upon the science system: Inadvertent consequences? Scientometrics, 62(1): 117-131.

White, H.D. and McCain, K.W. (1998). Visualizing a discipline: An author co-citation analysis of information science, 1972-1995. Journal of the American Society for Information Science, 49(4): 327-355.

Wouters, P. (1999). The Citation Culture. Amsterdam, NL: Universiteit van Amsterdam. Ph.D. Thesis.

Åström, F. (2007). Changes in the LIS research front: Time-sliced cocitation analyses of LIS journal articles, 1990-2004. Journal of the American Society for Information Science and Technology, 58(7): 947-957. 
Appendix 1. Journals included in the study.

\begin{tabular}{ll}
\hline Economics journals & Information science journals \\
\hline American Economic Review & Annual Review of Information Science and Technology \\
Brookings Papers on Economic Activity & Information Processing \& Management (and Information Storage \& \\
Canadian Journal of Economics & Retrieval) \\
Econometrica & Journal of the American Society for Information Science (and Journal \\
Economic Enquiry & of the American Society for Information Science and Technology) \\
Economic Journal & Journal of Documentation \\
Economica & Journal of Information Science \\
Economics Letters & Library \& Information Science Research (and Library Research) \\
European Economic Review & Proceedings of the American Society for Information Science \\
International Economic Review & (Proceedings of the ASIS Annual Meeting) \\
Journal of Development Economics & Scientometrics \\
Journal of Econometrics & Electronic Library \\
Journal of Economic Literature & Information Technology and Libraries (and Journal of Library \\
Journal of Economic Theory & Automation) \\
Journal of Financial Economics & Library Resources \& Technical Services \\
Journal of International Economics & Program-Automated Library and Information Systems \\
Journal of Labor Economics & \\
Journal of Law and Economics & High energy physics journals \\
Journal of Mathematical Economics & \\
Journal of Monetary Economics & Physical Review D \\
Journal of Political Economy & Physics Letters B \\
Journal of Public Economy & Nuclear Physics B \\
Oxford Economic Papers & \\
Quarterly Journal of Economics & \\
RAND Journal of Economics & \\
Review of Economic Studies & \\
Review of Economics and Statistics & \\
\hline & \\
& \\
\hline
\end{tabular}

